\title{
Epidemiological and phylogenetic analysis of rabies virus isolated from humans in Henan province, China
}

\author{
Jie Ma ${ }^{1}$. Sanjing $\mathrm{Li}^{1} \cdot$ Yuejie Yang ${ }^{1} \cdot$ Qiong Wang $^{1} \cdot$ Yuqi Huo $^{1}$
}

Received: 9 May 2019 / Accepted: 1 August 2019 / Published online: 30 August 2019

C) Springer-Verlag GmbH Austria, part of Springer Nature 2019

\begin{abstract}
Rabies remains a public health threat in China, and most transmissions are dog-mediated. In this study, we studied 31 clinically diagnosed human rabies patients that had been scratched or bitten by dogs. Real-time reverse transcription polymerase chain reaction (RT-qPCR) and nested RT-PCR were performed on saliva samples or cerebrospinal fluid, and samples from 28 patients tested positive for rabies virus. A total of one near-complete genome sequence, 15 complete glycoprotein $(\mathrm{G})$ gene sequences, and five partial G gene sequences were determined. Phylogenetic analysis was performed, based on complete G gene sequences, using the maximum-likelihood method. The results indicated that the isolates belonged to the lyssavirus genotype I lineage and China I lineage. The Chinese rabies virus can be divided into six major lineages. The China I lineage was the dominant clade and could be divided into four subclades. Isolates 17HN19, 17HN75, and 18HN162 fell within clade IC subgroup, and the other isolates were assigned to the clade IA subgroup. This study provides epidemiological and genetic information on rabies incidence in humans.
\end{abstract}

\section{Introduction}

Rabies is a neglected zoonotic disease with a fatality rate approaching $100 \%$ in humans once symptoms appear. Rabies causes approximately 59,000 deaths each year worldwide $[1,2]$. The annual number of human rabies cases in China is second only to that in India. Rabies virus (RABV) has more than 30 reported animal reservoir species and a nearglobal distribution [3]. Dogs remain the principal reservoir of rabies transmission to humans in developing countries, particularly in poor urban and rural areas [4]. More than $99 \%$ of human rabies cases are related to dogs, and over $90 \%$ of human rabies cases in China are reported in rural areas, where the proportion of free-roaming and unvaccinated dogs is high [5, 6]. From 2008 to 2016, rabies was the third most common cause of human deaths in the list of 39 notifiable

Handling Editor: William G Dundon.

Electronic supplementary material The online version of this article (https://doi.org/10.1007/s00705-019-04388-6) contains supplementary material, which is available to authorized users.

Yuqi Huo

1246105971@qq.com

1 The Sixth People's Hospital of Zhengzhou, Zhengzhou, People's Republic of China infectious diseases in China. By the end of 2017, this disease dropped one position and ranked as the fourth most common cause of human death [7]. Although official data show that human rabies cases have declined steadily since 2007, China is still a rabies-endemic country [8].

WHO has recommended the detection of rabies antigen by a fluorescent antibody test (FAT) on brain tissue obtained post-mortem as the "gold standard" for confirmation of rabies cases [9]. However, obtaining brain tissue after death in China is not feasible for traditional-culture-related reasons. Rabies is transmitted to people by direct contact with infected saliva via scratches or bites. Ribonucleic acid (RNA) detection in saliva is one of the recommended diagnostic tests for human rabies (ante-mortem) [9]. The glycoprotein $(\mathrm{G})$ of RABV is less conserved than the other proteins and contains major antigenic sites designated as I-VI, "a", and G1 on the ectodomain (ECTO, 439 amino acids) that allow the determination of virus origin $[10,11]$. The $\mathrm{G}$ protein is the viral antigen that elicits neutralizing antibodies and plays a crucial role in viral pathogenicity [12]. A site in the $G$ gene that is potentially under positive selection has been predicted. The $\mathrm{G}$ gene is used for molecular epidemiological studies, and the complete $\mathrm{G}$ gene has been employed as a marker to study the relationship between different viral isolates [13-17]. Studies have demonstrated that fundamental phylogenetic interpretations based on analysis 
of the complete $\mathrm{N}$ gene are equivalent to those based on the $\mathrm{G}$ gene [17-19].

In this study, the presence of the RABV genome in saliva or cerebrospinal fluids of clinically diagnosed rabies patients was detected by both real-time reverse transcription polymerase chain reaction (RT-qPCR) and nested RT-PCR. The complete $\mathrm{G}$ gene sequence was determined for the majority of the cases. Phylogenetic analysis based on the complete nucleotide sequences of the $\mathrm{G}$ gene was performed to characterize the clustering of positive strains with documented strains isolated from different provinces of China. These data provided a better understanding of the geographical pattern of RABV transmission in Henan province.

\section{Materials and methods}

A total of 31 patients, admitted to the Sixth People's Hospital of Zhengzhou from Jan 2017 to Dec 2018, were determined to have clinical rabies based on diagnostic criteria (WS281-2008). Saliva samples were collected from all patients, and CSF samples were collected from two patients. Viral RNA was extracted from each sample using a TaKaRa MiniBEST Viral RNA/DNA Extraction Kit Ver. 5.0 (TaKaRa, Dalian, China) according to the manufacturer's protocol. Complementary DNA (cDNA) was reverse transcribed using a RevertAid First-Strand cDNA Synthesis Kit (Thermo Fisher Scientific, USA). All saliva samples were tested for the presence of the RABV genome using an RTqPCR and a nested-PCR that amplifies a partial N-segment sequence [20]. The primers and the probe used for RT-qPCR are listed in Table 1. The RT-qPCR reaction mixture contained $2 \times$ One-Step RT-PCR Buffer III (TaKaRa, Dalian, China), $5 \mu \mathrm{l}$ of RNA, $0.4 \mu \mathrm{l}$ of TakaRa Ex Taq HS ( $5 \mathrm{U} / \mu \mathrm{l})$, $0.4 \mu \mathrm{l}$ of PrimeScript RT Enzyme Mix II, $0.4 \mu \mathrm{l}$ of ROX Reference Dye II (50×), RNAse-free water, $0.2 \mu \mathrm{M}$ (final concentration) sense and antisense primers, and $0.4 \mu \mathrm{M}$ (final concentration) probe in a final volume of $20 \mu 1$. The reaction was carried out on a 7500 Real-Time System Cycler (Applied Biosystems, USA) using the following thermal cycling profile: $42^{\circ} \mathrm{C}$ for $15 \mathrm{~min}, 95^{\circ} \mathrm{C}$ for $10 \mathrm{~s}$, followed by 45 cycles of $95^{\circ} \mathrm{C}$ for $5 \mathrm{~s}$ and $55^{\circ} \mathrm{C}$ for $40 \mathrm{~s}$. The RTqPCR product was sequenced. The primers used to amplify the whole genome or the complete $\mathrm{G}$ gene were designed based on the isolate SXBJ15 (GenBank accession number KR230089) (Supplemental Table 1). The PCR reaction mixture contained $2 \times$ Ex Taq Buffer (TaKaRa, Dalian, China), viral cDNA (300 ng), RNase-free water, and $0.4 \mu \mathrm{M}$ (final concentration) sense and antisense primers in a final volume of $50 \mu$ l. The amplification program was as follows: $95^{\circ} \mathrm{C}$ for $2 \mathrm{~min}$ and then 36 cycles of $95^{\circ} \mathrm{C}$ for $10 \mathrm{~s}, 55^{\circ} \mathrm{C}$ for 30 s, and $72^{\circ} \mathrm{C}$ for $40 \mathrm{~s}$, and a final extension at $72^{\circ} \mathrm{C}$ for 10 $\min$. For the amplification of the whole genome sequence, the same program was used except that annealing temperatures in the range of $55-60^{\circ} \mathrm{C}$ were used. The PCR products were extracted and sequenced in both directions using the Sanger sequencing method (Wuhan GeneCreate Biological Engineering Co., Ltd, China). The final sequences were assembled manually.

Multiple sequence alignment of the complete $G$ gene sequences from our 16 isolates and those from different provinces of China were performed using ClustalW in MEGA 7. The gene sequence information used in this study is shown in Supplemental Table 2. The parameter values for the best-fit model of nucleotide substitution were determined to be the Kimura 2-parameter model incorporating gamma distribution $(\mathrm{K} 2+\mathrm{G})$. A phylogenetic tree was inferred by maximum-likelihood (ML) reconstruction based on the aligned complete $\mathrm{G}$ gene nucleotide sequences, as implemented in the MEGA software. The statistical significance of the constructed phylogenetic tree was estimated by bootstrap analysis with 1000 pseudoreplicate datasets.

\section{Results}

The clinical rabies-positive patients $(\mathrm{n}=31)$ came from 14 municipalities in Henan province: Zhoukou $(\mathrm{n}=8)$, Pingdingshan $(n=5)$, Nanyang $(n=4)$, Shangqiu $(n=2)$, Xinxiang $(n=2)$, Puyang $(n=2)$, Zhumadian $(n=1)$, Zhengzhou $(\mathrm{n}=1)$, Xinyang $(\mathrm{n}=1)$, Sanmenxia $(\mathrm{n}=1)$, Kaifeng $(\mathrm{n}=$ $1)$, Luohe $(\mathrm{n}=1)$, Anyang $(\mathrm{n}=1)$ and Jiyuan $(\mathrm{n}=1)$. The geographic distribution of patients is shown in Fig. 1. All of the patients lived in rural areas. The male-to-female ratio was 1.58:1 (19 males, 12 females), and their ages ranged from 10 to 69 years, with 29 patients older than 40 . This
Table 1 Sequences of RT-qPCR primers and probes used in this study

\begin{tabular}{lllll}
\hline Name & Type & Sequence $\left(5^{\prime}-3^{\prime}\right)^{\mathrm{a}}$ & Position $^{\mathrm{b}}$ & Product size (bp) $^{\text {RV-F }}$ \\
Primer & GAACTTYGAGGAAGAGATAAGAAG & $859-882$ & \multirow{2}{*}{$138 \mathrm{bp}$} \\
RV-P & Probe & FAM-ARGAGACWGCTGTTCCTCAYT & $900-925$ & \\
& CCTAT-TAMRA & & \\
RV-R & Primer & AACACRTGACCMACWGCATTYGAT & $973-997$ & \\
\hline
\end{tabular}

${ }^{a}$ Degenerate primer; Y, C/T; R, A/G; W, A/T; M, A/C

${ }^{\mathrm{b}}$ Reference sequence SXBJ15 (GenBank no. KR230089) 


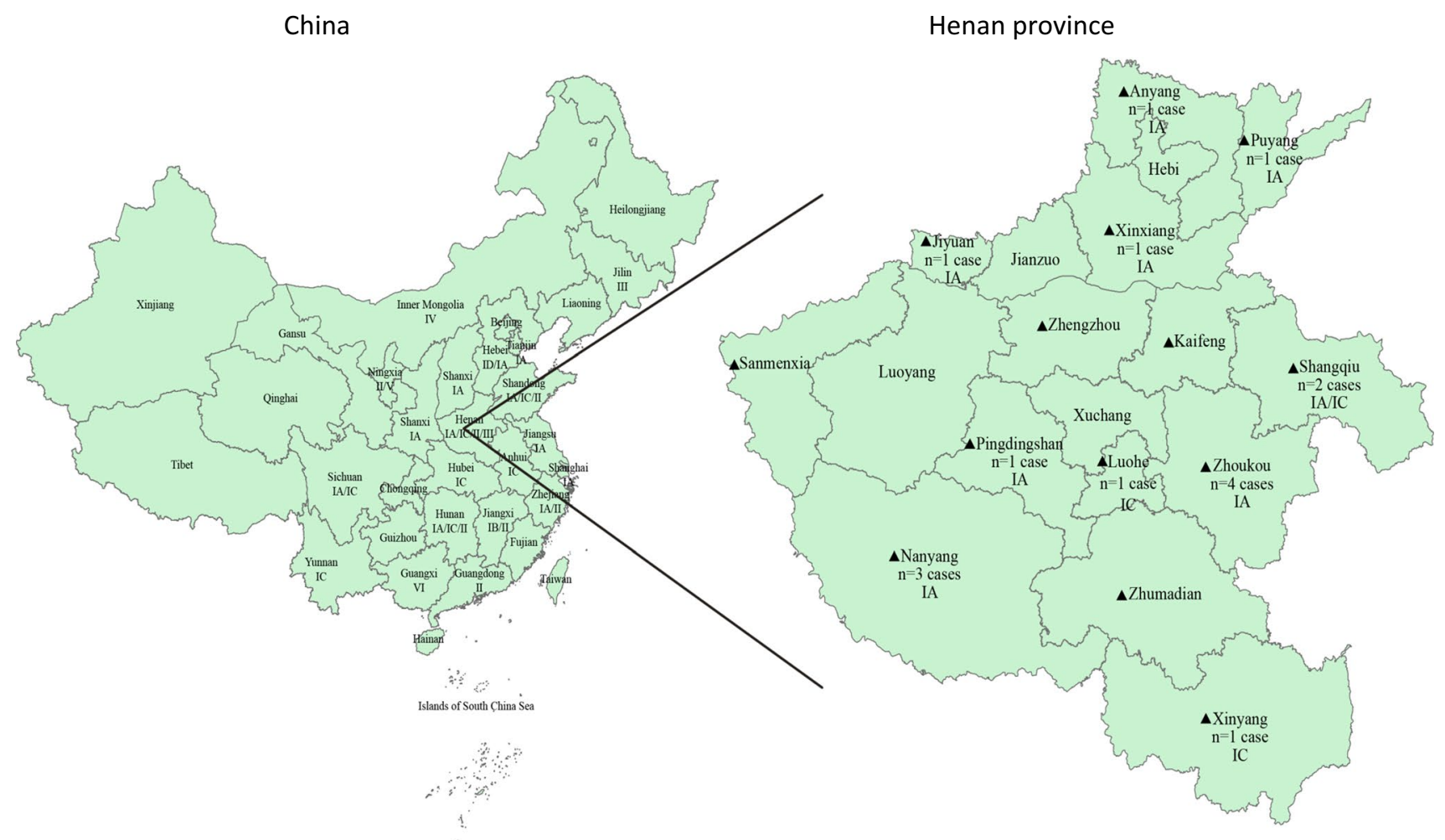

Fig. 1 Geographic distribution of reported rabies cases and detected clinical rabies cases in this study. IA, clade IA; IB, clade IB; IC, clade IC; ID, clade ID; II, clade II; III, clade III; IV, clade IV; V, clade V;

result was consistent with reports that concluded that most rabies cases occur in older males living in rural and remote areas [21, 22]. Two patients had an unknown exposure route. Of the 29 patients with a known history of exposure, 23 were scratched or bitten by free-roaming dogs; and six, by their own dog. A total of 22 patients began to have clinical symptoms within six months. Based on the severity of exposure, 13 patients were classified as having category II exposure and 16 as having category III (Supplemental Table 3). CSF samples were taken from two patients. Multiple saliva samples were collected from seven patients at different time points, and a single saliva sample was collected from the remaining patients. Most patients were discharged within 24 hours at the request of their family members.

We used RT-qPCR and nested PCR to detect the presence of rabies RNA. For RT-qPCR, the linear detection range was determined to be $10^{6}$ copies $/ \mathrm{ml}(\mathrm{Ct}=26)$ to $10^{2}$ copies $/ \mathrm{ml}(\mathrm{Ct}=38)$ of plasmid containing an amplified fragment. A Ct value less than 40 was considered to be positive. Saliva samples from 28 patients were positive by RT-qPCR, those from 19 patients were positive by nested-PCR, and those from three patients were negative by both RT-qPCR and nested PCR. Of the patients confirmed positive by RTqPCR, seven were negative by nested PCR due to a low RABV load in the saliva sample. Saliva samples from two
VI, clade VI, black triangle, clinical rabies-positive case; n, number of detected rabies cases

patients were positive by both RT-qPCR and nested PCR, while CSF samples from these patients were both negative. Detailed information is presented in Table 2.

Complete $\mathrm{G}$ gene sequences were determined for 15 patients, and a near-complete genome sequence was determined for one patient. Due to low viral loads in saliva samples, only partial $\mathrm{G}$ gene sequences were successfully amplified for five patients. The complete $\mathrm{G}$ gene sequences and the near-complete genome sequence were submitted to the National Center for Biotechnology Information (NCBI) database under accession numbers MH141794MH141801, MK622903-MK622908, MK840986, and KY780299. Sequence alignment indicated that the $\mathrm{G}$ genes of the 16 isolates exhibited a similarity of $97.6 \%-99.6 \%$ at the nucleotide sequence level and $97.7 \%-100 \%$ at the amino acid sequence level. The near-complete genome of $17 \mathrm{HN} 11$ (GenBank accession number KY780299) was determined to be $11,924 \mathrm{nt}$ in length and exhibited the highest similarity (97.37\% nt sequence identity) to that of a CJS0636D strain (GenBank accession number JQ970482) isolated in Jiangsu province, China. Phylogenetic analysis showed that the 16 isolates belonged to the lyssavirus genotype I lineage and the China I lineage. Based on our results and the grouping results reported by others [14], the China I lineage can be divided into four subclades. Isolates 17HN19, 17HN75 and 


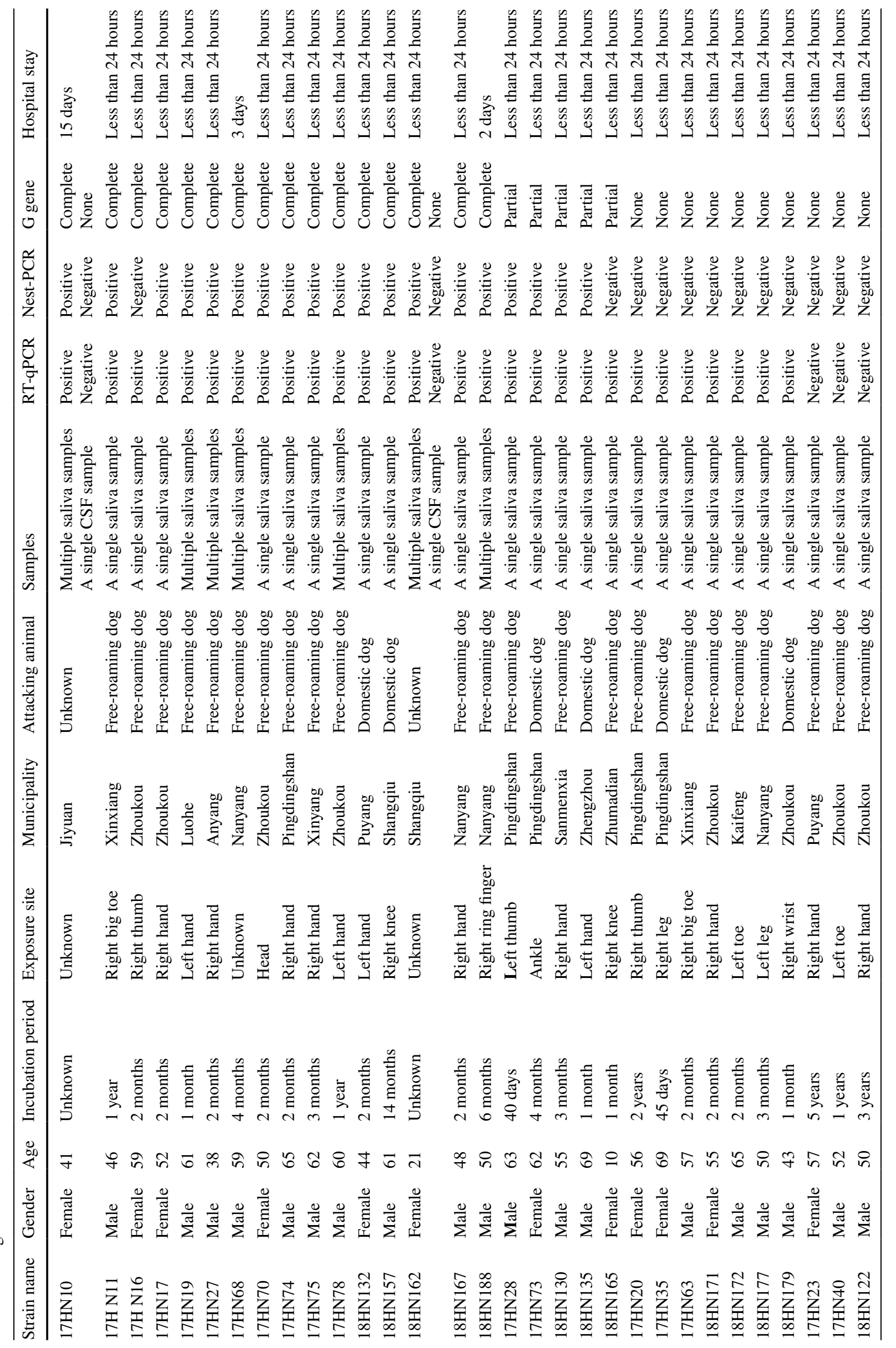


18HN162 were clustered with strains from Anhui, Hubei, and Shandong within the clade IC subgroup, and the other isolates were clustered with strains from Tianjin, Shanxi, Sichuan, and Shandong in the clade IA subgroup (Fig. 2). Evolutionary genetic analysis indicated that rabies was transmitted within and between regions. Isolate $17 \mathrm{HN} 10$ from Jiyuan clustered with isolates 17HN70, 17HN78, and
17HN16 from Zhoukou, and isolate 17HN17 from Zhoukou clustered with isolates $17 \mathrm{HN} 68,18 \mathrm{HN} 167$, and $18 \mathrm{HN} 188$ from Nanyang. The clustering of the 17HN11 strain with other rabies strains, based on the complete genome sequence, was also analyzed. The isolate $17 \mathrm{HN} 11$ belonged to the China I lineage and clustered with isolates D01 and D02 from Zhejiang province, China (Supplemental Fig. 1).

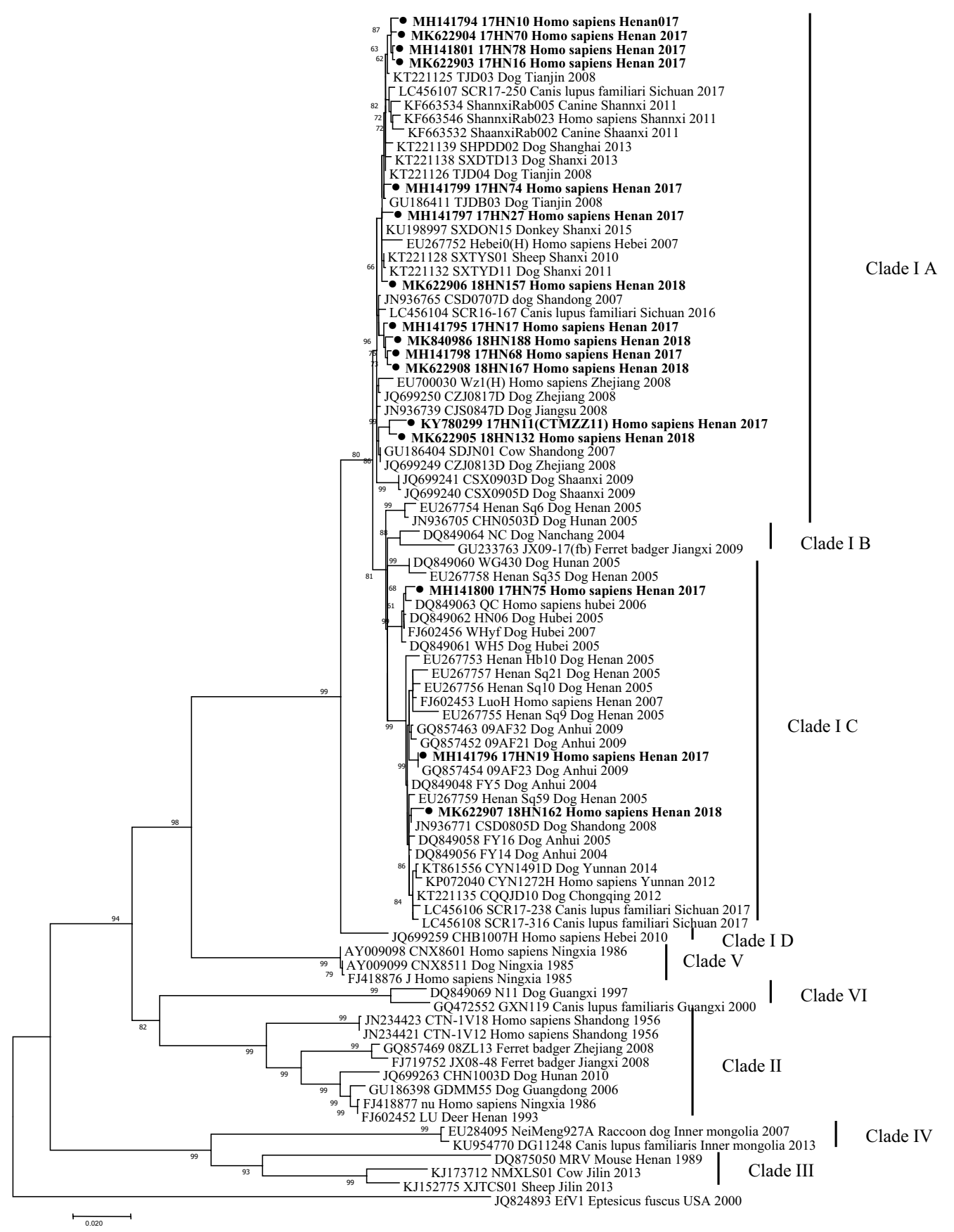

Fig. 2 Phylogenetic analysis based on the complete RABV G genes (1575 nt) of 16 Henan RABV isolates and isolates from other provinces of China by the maximum-likelihood (ML) method with 1000 bootstrap replicates. Only those with support values $>60 \%$ are shown at each node. The viruses isolated in this study are shown in bold. EfV1 virus was used as an outgroup. The accession number, strain name, host, province, and year of sample collection are indicated for each sequence 
This was consistent with the phylogenetic analysis results based on the complete $\mathrm{G}$ gene sequence.

\section{Discussion}

WHO proposed an ambitious worldwide goal in 2015: elimination of human deaths from dog-transmitted rabies by 2030 [23]. The theme for the 2017 World Rabies Day was "Rabies: zero by 30 ". This was intended to raise awareness about rabies prevention and the urgency of eliminating rabies. To achieve the goal of eliminating rabies, the Chinese Ministry of Agriculture issued a "National Animal Rabies Disease Prevention and Control Plan (2017-2020)." The plan stipulates that, by 2020, vaccination spots/sites should be established over the entire nation. The percentage of registered or managed dogs that are vaccinated should exceed $90 \%$, and all dogs receiving vaccination should be documented. Other aspects including improved diagnostic ability in county-level laboratories, a strictly implemented surveillance reporting system, enhanced government-based supervision activities, and enhanced rabiesrelated propaganda and education are described in the plan.

Rabies, once symptoms appear, is almost always fatal, but early vaccination following exposure can prevent the disease. In this study, the 31 patients all lived in rural areas and did not seek PEP vaccination after exposure (Supplemental Table 3). This scenario could be attributed to three reasons: i) people living in rural areas have high exposure risk because of the high proportion of unvaccinated and freeroaming dogs (5); ii) the health awareness of people living in rural areas, especially older people, is low; iii) and long-term poverty alleviation has improved the life of rural low-income people, but high out-of-pocket costs prevent some from seeking vaccination or PEP in a timely and effective way. With the development of the Internet, Network, WeChat, or Weibo may be useful tools for increasing health awareness [22]. To provide adequate knowledge about how to avoid exposure and how to deal with wounds after exposure, public settings such as hospitals, clinics, schools and communities of villages need to actively disseminate rabies-related information to the public, especially to children and the elderly.

Of the 31 patients with clinical symptoms of rabies, saliva samples of 28 patients were confirmed positive by RT-qPCR. A confirmative diagnosis of rabies for the other three patients with a clear history of exposure but negative results by both RT-qPCR and nested PCR could not be ruled out [9]. Most patients, including the three patients with negative results by both RT-qPCR and nested PCR, were discharged from hospital within 24 hours, so extra samples could not be taken for further verification. Given the potential risk of human-tohuman transmission, the best option for patients with clinical rabies is hospitalization where he/she can receive adequate and respectful palliative care $[9,24]$.
All of the 16 isolates belonged to clade I, which is endemic in China. Clade I replaced clade II and became dominant after 1990. The replacement of a dominant lineage may be related to mass dog culling [25]. Dog culling is a relatively ineffective and costly way of preventing rabies [25]. The World Organization for Animal Health (OIE) advocates that dogs should not be viewed as the accomplices that spread rabies but rather as the best partners to fight rabies. In pursuit of this goal, mass vaccination and largescale use of bait vaccines should be used. These actions have led to a dramatic decline in the number of rabies cases in South Korea [26]. Furthermore, it has been demonstrated that reduction of the prevalence of a pathogen in animal host populations by vaccination contributes to minimization of the risk of human infection [27, 28].

The death toll from human rabies in China has substantially declined from 1128 cases in 2013 to 426 cases in 2018 [29], but ending all human deaths from dog-transmitted rabies by 2030 remains an ambitious goal. Human rabies cases in China have been reported in all provinces except Taiwan. Henan is a densely populated agricultural province, and there were more than 80 reported human rabies cases per year from 2013 to 2016 [30]. Although this number declined to 46 in 2018, our data showed that human rabies cases occurred in 14 of 18 municipalities in Henan province. This suggests that dog-transmitted rabies remains widespread and is a serious public health problem. Human rabies prevention and control in rural areas is vital to eliminate dog-transmitted human rabies in Henan province. People living in the rural regions, especially Zhoukou, Pingdingshan, and Nanyang, have a higher risk of exposure to rabies virus. Population control of free-roaming dogs, strict vaccination of domestic dogs, and education about rabies prevention are important and effective ways of reducing or eliminating dog-transmitted human rabies. In this study, we provided information about the epidemiology and genetics of rabies in Henan province, as well as the measures taken by people after rabies exposure. This information might be useful in guiding government policy decision-making for fighting against this deadly disease.

Author contributions $\mathrm{YH}$ conceived and designed the experiments. JM and QW performed the experiments. SL and YY collected the samples. $\mathrm{JM}$ analyzed the data and prepared the manuscript. YH revised the manuscript.

\section{Compliance with ethical standards}

Conflict of interest The authors declare no conflicts of interest.

Human/animal rights statement This article does not contain any studies with human participants or animals performed by any of the authors. 


\section{References}

1. Li GW, Chen QG, Qu ZY, Xia Y, Lam A, Zhang DM et al (2015) Epidemiological characteristics of human rabies in Henan province in China from 2005 to 2013. J Venom Anim Toxins Incl Trop Dis 21:34 (PubMed PMID: 26336373, Pubmed Central PMCID: 4557598, Epub 2015/09/04. eng)

2. Baghi HB, Bazmani A, Aghazadeh M (2016) The fight against rabies: the Middle East needs to step up its game. Lancet 388(10054):1880 (PubMed PMID: 27692479, Epub 2016/10/19. eng)

3. Ma X, Monroe BP, Cleaton JM, Orciari LA, Li Y, Kirby JD et al (2018) Rabies surveillance in the United States during 2017. J Am Vet Med Assoc 253(12):1555-1568 (PubMed PMID: 30668262, Epub 2019/01/23. eng)

4. Hampson K, Coudeville L, Lembo T, Sambo M, Kieffer A, Attlan $\mathrm{M}$ et al (2015) Estimating the global burden of endemic canine rabies. PLoS Negl Trop Dis 9(4):e0003709 (PubMed PMID: 25881058, Pubmed Central PMCID: 4400070. Epub 2015/04/17. eng)

5. Tian H, Feng Y, Vrancken B, Cazelles B, Tan H, Gill MS et al (2018) Transmission dynamics of re-emerging rabies in domestic dogs of rural China. PLoS Pathog 14(12):e1007392 (PubMed PMID: 30521641, Pubmed Central PMCID: 6283347, Epub 2018/12/07. eng)

6. Fooks AR, Banyard AC, Horton DL, Johnson N, McElhinney LM, Jackson AC (2014) Current status of rabies and prospects for elimination. Lancet 384(9951):1389-1399 (PubMed PMID: 24828901, Epub 2014/05/16. eng)

7. National Health Commission of the People's Republic of China. http://www.nhc.gov.cn/jkj/s3578/201802/de926bdb046749a bb7b0a8e23d929104.shtml (chinese)

8. Yin W, Dong J, Tu C, Edwards J, Guo F, Zhou H et al (2013) Challenges and needs for China to eliminate rabies. Infect Dis Poverty 2(1):23 (PubMed PMID: 24088366, Pubmed Central PMCID: 3851465, Epub 2013/10/04. eng)

9. WHO (2018) Expert consultation on rabies. Third report. WHO, Geneva

10. Yang DK, Park YN, Hong GS, Kang HK, Oh YI, Cho SD et al (2011) Molecular characterization of Korean rabies virus isolates. J Vet Sci 12(1):57-63 (PubMed PMID: 21368564, Pubmed Central PMCID: 3053468, Epub 2011/03/04. eng)

11. Troupin C, Dacheux L, Tanguy M, Sabeta C, Blanc H, Bouchier $\mathrm{C}$ et al (2016) Large-scale phylogenomic analysis reveals the complex evolutionary history of rabies virus in multiple carnivore hosts. PLoS Pathog 12(12):e1006041

12. Zhang G, Wang H, Mahmood F, Fu ZF (2013) Rabies virus glycoprotein is an important determinant for the induction of innate immune responses and the pathogenic mechanisms. Vet Microbiol 162(2-4):601-613

13. Meng SL, Yan JX, Xu GL, Nadin-Davis SA, Ming PG, Liu SY et al (2007) A molecular epidemiological study targeting the glycoprotein gene of rabies virus isolates from China. Virus Res 124(1-2):125-138 (PubMed PMID: 17129631, Epub 2006/11/30. eng)

14. Lang SL, Tao XY, Guo ZY, Tang Q, Li H, Yin CP et al (2012) Molecular characterization of viral $\mathrm{G}$ gene in emerging and re-emerging areas of rabies in China, 2007 to 2011. Virol Sin 27(3):194-203 (PubMed PMID: 22684474, Epub 2012/06/12. eng)

15. Cherian S, Singh R, Singh KP, Manjunatha Reddy GB, Ravi Kumar G et al (2015) Phylogenetic analysis of Indian rabies virus isolates targeting the complete glycoprotein gene. Infect Genet Evol 36:333-338 (PubMed PMID: 26427850, Epub 2015/10/03. eng)
16. Brunker K, Marston DA, Horton DL, Cleaveland S, Fooks AR, Kazwala R et al (2015) Elucidating the phylodynamics of endemic rabies virus in eastern Africa using whole-genome sequencing. Virus Evol 1(1):vev011

17. Benjathummarak S, Fa-Ngoen C, Pipattanaboon C, Boonha K, Ramasoota P, Pitaksajjakul P (2016) Molecular genetic characterization of rabies virus glycoprotein gene sequences from rabid dogs in Bangkok and neighboring provinces in Thailand, 2013-2014. Arch Virol 161(5):1261-1271 (PubMed PMID: 26887972, Epub 2016/02/19. eng)

18. Coetzer A, Gwenhure L, Makaya P, Markotter W, Nel L (2019) Epidemiological aspects of the persistent transmission of rabies during an outbreak (2010-2017) in Harare, Zimbabwe. PLoS One 14(1):e0210018 (PubMed PMID: 30629634, Pubmed Central PMCID: 6328171, Epub 2019/01/11. eng)

19. Zhang S, Zhao J, Liu Y, Fooks AR, Zhang F, Hu R (2010) Characterization of a rabies virus isolate from a ferret badger (Melogale moschata) with unique molecular differences in glycoprotein antigenic site III. Virus Res 149(2):143-151 (PubMed PMID: 20109507, Epub 2010/01/30. eng)

20. Vázquez-Morón S, Avellón A, Echevarria JE (2006) RT-PCR for detection of all seven genotypes of Lyssavirus genus. J Virol Methods 135(2):281-287

21. Zhou H, Vong S, Liu K, Li Y, Mu D, Wang L et al (2016) Human rabies in China, 1960-2014: a descriptive epidemiological study. PLoS Negl Trop Dis 10(8):e0004874 (PubMed PMID: 27500957, Pubmed Central PMCID: 4976867, Epub 2016/08/09. eng)

22. Qi L, Su K, Shen T, Tang W, Xiao B, Long J et al (2018) Epidemiological characteristics and post-exposure prophylaxis of human rabies in Chongqing, China, 2007-2016. BMC Infect Dis 18(1):6 (PubMed PMID: 29295708, Pubmed Central PMCID: 5751830, Epub 2018/01/04. eng)

23. Mohammadi D (2016) Moves to consign rabies to history. Lancet Infect Dis 16(10):1115-1116 (PubMed PMID: 27676351, Epub 2016/09/28. eng)

24. Guo C, Li Y, Huai Y, Rao CY, Lai S, Mu D et al (2018) Exposure history, post-exposure prophylaxis use, and clinical characteristics of human rabies cases in China, 2006-2012. Sci Rep $8(1): 17188$

25. Tao XY, Tang Q, Rayner S, Guo ZY, Li H, Lang SL et al (2013) Molecular phylodynamic analysis indicates lineage displacement occurred in Chinese rabies epidemics between 1949 to 2010. PLoS Negl Trop Dis 7(7):e2294

26. Yang DK, Kim HH, Lee KK, Yoo JY, Seomun H, Cho IS (2017) Mass vaccination has led to the elimination of rabies since 2014 in South Korea. Clin Exp Vaccine Res 6(2):111-119

27. Trewby H, Nadin-Davis SA, Real LA, Biek R (2017) Processes underlying rabies virus incursions across US-Canada border as revealed by whole-genome phylogeography. Emerg Infect Dis 23(9):1454-1461

28. Basinski AJ, Nuismer SL, Remien CH (2019) A little goes a long way: Weak vaccine transmission facilitates oral vaccination campaigns against zoonotic pathogens. PLoS Negl Trop Dis 13(3):e0007251 (PubMed PMID: 30849126, Pubmed Central PMCID: 6426267, Epub 2019/03/09. eng)

29. National Health Commission of the People's Republic of China. http://www.nhc.gov.cn/jkj/s3578/201904/050427ff32704a5 db64f4ae1f6d57c6c.shtml (chinese)

30. Health commission of Henan Province. http://www.hnwsjsw.gov. $\mathrm{cn} /$ channels/456.shtml (chinese)

Publisher's Note Springer Nature remains neutral with regard to jurisdictional claims in published maps and institutional affiliations. 